\title{
Educational area for learning of optics and technologies: union of open laboratories of ideas, methods and practices (OLIMP)
}

Maksim Ivashchenko, Kirill Bodrov, Nadezhda Tolstoba

Maksim Ivashchenko, Kirill Bodrov, Nadezhda Tolstoba, "Educational area for learning of optics and technologies: union of open laboratories of ideas, methods and practices (OLIMP)," Proc. SPIE 9946, Optics Education and Outreach IV, 994613 (27 September 2016); doi: 10.1117/12.2238002

EDIE Event: SPIE Optical Engineering + Applications, 2016, San Diego, California, United States 


\title{
Educational area for learning of optics and technologies: union of Open Laboratories of Ideas, Methods and Practices (OLIMP)
}

\author{
Maxim Ivashchenko, Kirill Bodrov, Nadezhda Tolstoba \\ ITMO University, 49 Kronverksky av., St. Petersburg, 197101, Russian Federation
}

\begin{abstract}
The paper deals with the concept of creating the union of Open Laboratories of Ideas, Methods and Practices (OLIMP). It describes the structure designed to simplify the relationship, such as business incubators, start-up accelerators, small innovative enterprises, fabrication laboratories and student centers. We consider their advantages and disadvantages for the specific audience of students and enthusiasts who do not have funding for their own projects.

The experience of interaction between the Open Laboratories of Ideas, Methods and Practices and the Student Research Laboratory for Optical Engineering shows the relative impact of structures on each other and the value of using such interaction in the learning process.

The paper also addresses issues such as: the motivation of students, enthusiasm for the direction the lab participants identify and maintain the initiatives, profiling in the design, scientific, commercial, social sphere.
\end{abstract}

Keywords: self-education, technology, motivation, optical projects, enthusiasm, technical creativity, open laboratory.

\section{INTRODUCTION}

A transmission and assimilation of knowledge - the extensive and dynamic thematic. In the educational process it can be generalized to allocate three subjects: the student, the university, the employer. Everyone has their own opinion on the educational process and its results. In most cases, these views differ quite strongly. This is due to the different fields of activity of each subject and burdened their own goals and objectives.

The employer is primarily engaged in business and production processes that requiring new specialists for him. More and more companies realize that providing a comfortable working environment for the employee increases labor productivity. The issue of maintaining enthusiasm, personal motivation and interest of the employee in his work is more difficult. Therefore, not every employer wants to spend time and resources to use an individual approach to the work of each employee. But there are examples of such companies in Russia and abroad. As a rule, these are young companies that occupy quite specific industries. Universities try to mediate between students and employers, properly preparing first. In such circumstances, many training programs become irrelevant quickly.

In this way, student has to deal with all the variety of possibilities offered by higher education institutions, and to try to correlate them with the dynamics of the labor market changes. Such a challenge for many unprepared students is daunting. Knowing this, universities and employers conduct open houses, arrange field trips and other activities aimed at profiling the students.

\section{OLIMP CREATION}

The organization named OLIMP began working in February 2014 in the ITMO University.

The main purpose of OLIMP is to begin working with enthusiastic students eager to obtain skills and competences, whose research projects are aimed at the integration of different areas of science.

The laboratory tasks:

- Providing a comfortable environment for project work;

- Provision of tools and materials, co-working areas for teamwork, equipment for rapid prototyping;

Optics Education and Outreach IV, edited by G. Groot Gregory, Proc. of SPIE Vol. 9946, 994613

(C) 2016 SPIE · CCC code: $0277-786 \mathrm{X} / 16 / \$ 18 \cdot$ doi: $10.1117 / 12.2238002$ 
- Organization of experience exchange between professionals and students, consultations with specialists, cultural, artistic and recreational activities;

- Professional orientation of students in the educational, scientific and project activities;

- Study of the problems associated with the lack of motivation of students to quality education.

A more ambitious goal of the OLIMP:

- The gradual formation of a personnel reserve the initiative of professionals with complementary competencies and have sufficient motivation, with the help of which it is possible independently to fill knowledge gaps or obtain new ones;

- Creation of knowledge networks, experts, materials similar to model a resource-based economy.

Similar structures have long been developed in Russia and abroad (as a rule, on the basis of higher educational institutions). In both cases, the departments and university faculties form student centers, start-up accelerators, incubators, small innovative enterprises and Fab Labs. Each of these structures has its own goals and guide students in different directions. The purpose of student centers often serves as a link between external companies and students wishing to study and gain practical experience of working on applied problems. Start-up accelerators and incubators designed to help students with access to an independent commercial activity, providing necessary consultations mentors and attracting sponsors and investors. Small innovative companies at universities perform a similar function, but the scope of their interests often overlaps with science, so often they are talking about interaction with grants in the framework of actual R \& D. A unique phenomenon in its time was the emergence of Fab Labs (Fabrication Laboratory).

The main purpose of Fab Lab was helping students to work on the application component of the final qualifying works of students of technical specialties. As a rule it is a rapid prototyping and development of various gadgets. For this Fab Labs equipped with modern facilities, such as 3D-printers and scanners, laser engravers, CNC machines, UV printers, and more. Thus the student has access to the industrial equipment, assembled in one place, it provides complete prototyping cycle for rather complicated devices.

In the field of optical education for a long time there was interest in the development of practice-oriented initiative of associations of students, allowing to work on creative projects.

Accordingly, the Student research laboratory for optical engineering (SRLOE) was opened a few years ago [1].

In 2015, OLIMP and SRLOE joined forces and began to work together. This proved to be a valuable experience for both OLIMP and for SRLOE.

Workshops work system has been used with success in SRLOE lab and brought interesting results.

Many students educational and research projects need more than each of these systems can give. Fab Labs not focused on teaching students who do not know the skills for creating and editing three-dimensional models and drawings. As a result, students of humanitarian specialties by default can no longer go there and, respectively, social projects are not implemented. Furthermore, even technical specialties students are not always prepared to interact with Fab Labs. Business incubators in the vast majority tend to commercialization activities of students, provide additional knowledge and experts in the fields of marketing and economics but can not give any production capacity of the Fab lab or practice of student centers. However, they (as the small innovative enterprises) work with already-formed ideas and projects. Student centers are often directed either toward consulting in management, economy and marketing, a focus on educational practice in specific areas: information technology, optics, robotics, and others.

OLIMP brings together parts of each of the above structures and forms of their work on a single cycle of teaching and practical projects with the possibility of further development of their business, scientific, educational or social projects.

The OLIMP at the moment consists of the following groups:

- Members. Enthusiasts seeking to acquire new knowledge and skills. Mostly students.

- Master. Enterprising professionals already possess the skills and voluntarily willing to share their knowledge with others.

- Mentors. Skilled craftsmen, or invited experts, capable to serve as experts in rather trivial matters. 
- Active Members (Active). The initiative group, which takes an active part in almost all activities of the laboratory, whether recital or repair work.

- Organizers. They are a core of the Lab, a coordinating function that determines the development of the system and at the same time being the guardians of the ideological content of the entire structure.

Each group may include anyone. This is not necessarily a student of the University ITMO. At this point in the activities of OLIMP involved students and graduates of Saint-Petersburg and Moscow, the students, teachers, scientists.

\section{DESCRIPTION OF THE ORGANIZATION'S STRUCTURE}

There are two organizes at the head of the laboratory. They are selected in the way, that they can easily complement each other, because of differences in character, way of thinking, in aspects of knowledge and skills. For example, one of them can be more emotional in communication, when the other one can state systemically and reservedly. The main factors, that combine them, are: the same vision of OLIMP's structure, united values and the high level of reciprocal trust. Such approach is a kind of precedent for different other organizations.

Another organization group includes masters and active participants of the laboratory. Usually, it consists of the most interested in the development of OLIMP's conception. With their help project groups are formed. Also, they discuss and correct long-term decisions, participate in conferences, festivals and make the organizational plan of different events. Every week this group meets on the planning session, to discuss the most important organizational issues. Also, they take part in master classes, devoted to management, teaching and workshop's organization.

In this system, the optical directional initiative projects were easy to fit into the structure of the OLIMP workshops and learn from the experience of work and rules for the organization of workshops.

And the interaction with other areas helped successfully transform ideas into real optical instrument, to produce equipment and have the opportunity to consult with experienced colleagues on issues of robotics, instrumentation, mechanics and so on [2].

\section{WORKSHOPS}

Educational and practical activity is organized in workshops. Studies start at the fourth week after the term starting. They are held from 6 to 10 p.m. After two months workshops presents their results at a final point, that summaries their progress. Such measure is called "The Festival of Ideas and Projects". It starts a month before the term will be over to give students time to get ready for the exams and to go around the problem of the lack of time. So their activity in OLIMP does not obstruct their main study. In the current structure of laboratory one can distinguish three types of workshops: educational, project and scientific. Each of them includes educational, practical, project and scientific activity, but in a different quantitative sense, according to priorities.

Educational workshops are also divided into base and advanced, according to the knowledge and skills that are necessary to join it. There are no objectives to join the base workshop, but you should be ready to have some knowledge or a big desire to acquire it in a short time to join the advanced one. The future participants are selected by the master of each workshop. Study is based on a compulsory curriculum. Two or three weeks before the final festival the workshop begins to prepare: each student creates his own project and does it himself. Masters assume the role of experts instead of teachers and prompt the right direction if someone has a problem. That is the way transforming theoretical knowledge into practical and how an experience of independent search for an answer is inculcated. In educational workshops scientific activity is represented by meetings with scientists and participating in master classes. In additional, master gives advice on how to direct a project into scientific or commercial turn.

So students come through the additional profiling, after which they can thought about future development or their idea: quality improvement, increasing the project size, access to start-up accelerators and business incubators, creation a small innovative business. 
The base of the project workshop is a project realization. Master formulates objectives to each project as a kind of technical assignment with an individual plan. It depends on the number and the professional level of group's members. Also, financing availability, the delivery date of materials and the complexity of realization are taken into account. Such activity gives not only theoretical knowledge, but a real experience. An educational part is represented by a series of master classes on the necessary topics, if there are gaps in one's knowledge. Scientific part and profiling are inputted as in educational workshops, but in a more serious way: in the first case it means educational nature and the second one it is more specialized and affects deeper questions. After being in a project workshop a lot of students become masters and create their own projects. The workshop usually consists of about five or six people, who form a single whole. If a workshop leads two or more projects, it forms a special team for each of it. Master works as an expert, monitoring all the projects. Also, each group has its responsible one like a team-leader in IT.

The scientific workshop is based on a plan of scientific work. Postgraduates or scientists lead such groups as masters. Educational part is included when needed. Instead of project activity we have: planning and realization of experiments result processing, formalizing the publications and participant at different conferences. Such workshop attracts not only specialists, but also those, who have not got any scientific experience. Both of them communicate with each other, sharing their knowledge and ideas.

\section{PROJECT ACTIVITIES}

Project activity in OLIMP has two ways: a project workshop or a project section. Usually project workshops are organized around someone's project. This variant suits if there is:

- Lack of funding;

- Master wants to gather a temporary team of well-prepared specialists to solve a complicated problem;

- Master wants to prepare new specialists, to forming a constant team in the future.

All the projects that were initiated outside the OLIMP are directed to the project section (it consists of specialists, organizes and experienced masters). The expert group forms a team to work on the project when the preliminary approval of the terms of its implementation is completed. A participant of OLIMP or any invited specialist can join it.

There are four forms of projects:

- Implementation of project "turn-key". Financing of the materials and working is supposed. The project is carried out from the beginning to the end. All characteristics and the appearance of the project conform to customer's objectives: experts do not try to change anything in it. The main consumers are: commercial and business organizations, institutes of higher education, schools.

- Implementation of one part of the project. It is similar to the first variant. The main distinction is that OLIMP takes up work, which can not make the customer. For example, a student prepares a commercial project for which he must do a 3D model of city block, but he has not got any skills in 3D-modelling and there is no place, where he can print it. In such case a project team does this work for him and provides all the equipment and materials for making 3D models of his project. It is worth noting that such approach applies only to the commercial projects.

- Service sharing. It is the first approaching to realization of the resource-oriented net in OLIMP. It means, that one can exchange not only "service - to service", but also "service - equipment", "skills - materials" and so on. For example, the customer is given all the materials and OLIMP's equipment; instead of it he refines this equipment. This approach is popular in conditions of the lack of financing of non-commercial projects.

- Including to the project workshop. A lot of students appeals to the laboratory, because they have some skills and knowledge and can easily transmit it to others. Usually, it is a unit, noncommercial project. Instead of being provided with some space and equipment the customer qualifies and becomes a master.

It is worth noting that OLIMP gratis offers its ideas for the development of noncommercial projects: its appearance and realization, construction, documentation, marketing promote and so on. This approach is like a principle, to support 
projects of youth, ecological and social projects, projects that popularize the healthy lifestyle and lead to the increase of cultural and moral condition of the youth.

Many optical projects are carried out in the SRLOE in conjunction with technical workshops of OLIMP, and this is the best obtained results are obvious advantages and work together [1].

The scientific activity of the OLIMP has started its first step of development. The main contribution to it is from the individual performances of the OLIMP participants at the conferences and congresses, publications and scientific workshop activity.

\section{THE FESTIVAL OF IDEAS AND PROJECTS}

The festival of Ideas and Projects serves many purposes at the same time:

- Summarizes the activities of OLIMP once every six months;

- Presents the projects to external organizations and stakeholders;

- Encourages enthusiasts to participate in such activities, brainstorming and the development of their own projects;

- Demonstrates how to start working on an interesting and useful project in spite of different constraints (the lack of knowledge, experience, financial, advertising support, etc.);

- Attracts the commercial and business community to support youth projects and initiatives in the early stages of work;

- Shows what skills you can master in two months, participating in the activities of OLIMP.

In additional, the profession-oriented feature of the Festival should be mentioned: participants of workshops in different fields can see the results of each other, assess what other participants have achieved at the same time, can observe how their colleagues solved similar problems. Thus giving the participants of the training workshop an understanding of how much time they need to finish their own projects or to work out a scientific component of their current activity. Some workshops discuss joint projects for the next six months, share experiences and enhance communication with each other after the Festival. The result of this exchange is the new ideas for projects, improvement of existing projects and development of the overall structure and concepts of OLIMP.

\section{RESULTS}

Many results were achieved in the academic year 2014-2015 since Open Laboratory of Ideas, Methods and Practices has opened:

- Two areas basing on friend relationships joined OLIMP in the second part of the school year and formed the Union of the OLIMP;

- Amount of participants attending OLIMP workshops in a week: more than 100 people in the first half, more than 150 in the second part of the year (all classes are held in the same classroom with an area of 45 sq. $\mathrm{m}$. between 18 and 22 hours 6 days a week). Additional places are also regularly used, but only the basic place was taken for statistics;

- The total number of participants attending the Union OLIMP workshops: more than 300 people a week.

- Number of workshops: 9 in the first half, 11 in the second (the first place). The total number of workshops after the creation of the Union of Open Laboratories of Ideas, Methods and Practices: 16 (at the three places).

- For the first half of a year there were implemented 36 projects and conducted 37 events; 
- The number of hours of workshops per week: up to 50 hours in the first half of a year (some workshops are conducted in different zones of the main place at the same time);

- The amount of graduating works, realized on the base of OLIMP: 5 for the first half of the year;

- The number of OLIMP participants, presented at the conferences: more than 30;

- $\quad$ Conducted tours for schools: 3.

In the laboratory SRLOE during joint work carried out:

- Equipping the laboratory facilities for demonstration of optical phenomena;

- Implemented dozens of projects;

- Conducted many workshops on optics, photonics, light engineering;

- Carried out numerous activities with students.

In 2015-2016, the OLIMP Union is planning:

- Increase the number of workshops and workplaces;

- The beginning of commercial activity and the formation of a Fund to support projects;

- Attracting enthusiasts to participate in workshops and create their own laboratories;

- Networking with manufacturing enterprises;

- Extension of the resource-based network of knowledge sharing, equipment, materials and services;

- The establishment of a branch of OLIMP abroad.

\section{CONCLUSION}

Describes work to create an Open Laboratory of Ideas, Methods and Practices (OLIMP), with subsequent development in the Union of OLIMP was conducted by the students with support of teachers. In the 2013-2014 academic year as a small club. In 2014-2015 academic year as a full-featured lab, but still self-organization. At the moment, on the basis of OLIMP is preparing the creation of small innovative enterprises, the allocation of commercial structure in the main site, the creation of school educational center. The laboratory of the union actively participate in many contests, conferences, festivals and forums where they share their experiences.

It should be noted that the inclusion of the Student Research Laboratory for Optical Engineering in cooperation with OLIMP, has brought significant progress in the field of vocational guidance of students in optics. Students are engaged in technical creativity, work on projects, developing scientific activities.

In addition to the implementation of its main activities is also contributing to the profiling of youth and formation of a reserve of highly motivated and independent professionals.

\section{REFERENCES}

[1] Tolstoba, N.D., Saitgalina, A.K., Abdula, P.A., Butova, D.V. "Student research laboratory for optical engineering," Proc. SPIE 9793, 97931Y (2015).

[2] Saitgalina, A.K., Mitiushkin, A.V., Tolstoba, N.D. "Research of limits of applicability of an open-source equipment for development the optical equipment kit," Proc. SPIE 9889, 98891W (2016). 